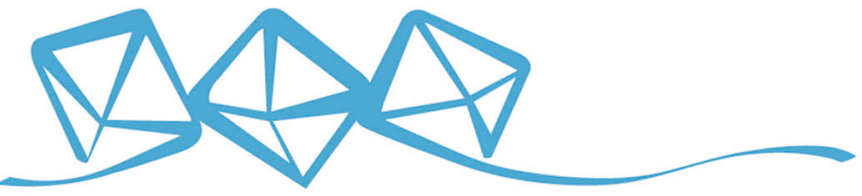 COMMUNICATIONS MATERIALS
}

ARTICLE

https://doi.org/10.1038/s43246-020-00095-x

OPEN

\section{Future material demand for automotive lithium-based batteries}

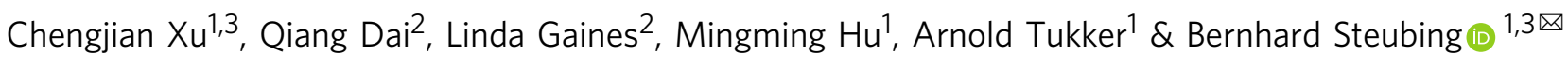

The world is shifting to electric vehicles to mitigate climate change. Here, we quantify the future demand for key battery materials, considering potential electric vehicle fleet and battery chemistry developments as well as second-use and recycling of electric vehicle batteries. We find that in a lithium nickel cobalt manganese oxide dominated battery scenario, demand is estimated to increase by factors of 18-20 for lithium, 17-19 for cobalt, 28-31 for nickel, and 15-20 for most other materials from 2020 to 2050, requiring a drastic expansion of lithium, cobalt, and nickel supply chains and likely additional resource discovery. However, uncertainties are large. Key factors are the development of the electric vehicles fleet and battery capacity requirements per vehicle. If other battery chemistries were used at large scale, e.g. lithium iron phosphate or novel lithium-sulphur or lithium-air batteries, the demand for cobalt and nickel would be substantially smaller. Closed-loop recycling plays a minor, but increasingly important role for reducing primary material demand until 2050, however, advances in recycling are necessary to economically recover battery-grade materials from end-of-life batteries. Second-use of electric vehicles batteries further delays recycling potentials.

\footnotetext{
${ }^{1}$ Institute of Environmental Sciences (CML), Leiden University, 2300 RA Leiden, The Netherlands. ${ }^{2}$ ReCell Center, Argonne National Laboratory, Lemont, IL, USA. ${ }^{3}$ These authors contributed equally: Chengjian Xu, Bernhard Steubing. ${ }^{凶}$ email: b.steubing@cml.leidenuniv.nl
} 
E lectric vehicles (EVs) generally have a reduced climate impact compared to internal combustion engine vehicles ${ }^{1}$. Together with technological progress and governmental subsidies, this advantage led to a massive increase in the demand for $\mathrm{EVs}^{2}$. The global fleet of light-duty EVs grew from a few thousand just a decade ago to 7.5 million vehicles in $2019^{3}$. Yet, the global average market penetration of EVs is still just around $1.5 \%$ in 2019 and future growth is expected to dwarf past growth in absolute numbers ${ }^{3}$.

Lithium-ion batteries (LIBs) are currently the dominant technology for EVs ${ }^{2}$. Typical automotive LIBs contain lithium (Li), cobalt (Co), and nickel (Ni) in the cathode, graphite in the anode, as well as aluminum and copper in other cell and pack components. Commonly used LIB cathode chemistries are lithium nickel cobalt manganese oxide (NCM), lithium nickel cobalt aluminum oxide (NCA), or lithium iron phosphate (LFP), although battery technology is currently evolving fast and new and improved chemistries can be expected in the future ${ }^{2,4}$.

Due to the fast growth of the EV market, concerns over the sustainable supply of battery materials have been voiced. These include supply risks due to high geopolitical concentrations of cobalt ${ }^{5,6}$ and social and environmental impacts associated with mining ${ }^{7,8}$, as well as the availability of cobalt and lithium reserves $^{9}$ and the required rapid upscaling of supply chains to meet expected demand ${ }^{5}$.

Understanding the magnitude of future demand for $\mathrm{EV}$ battery raw materials is essential to guide strategic decisions in policy and industry and to assess potential supply risks as well as social and environmental impacts. Several studies have quantified the future demand for EV battery materials for specific world regions such as Europe ${ }^{10}$, the United States ${ }^{11,12}$, and China ${ }^{13}$, or for specific battery materials only ${ }^{14-16}$. Weil et al. ${ }^{9}$ assess the material demand for EV batteries at the global level and find that shortages for key materials, such as Li and $\mathrm{Co}$, can be expected. However, their model does not investigate the influence of battery chemistry developments (e.g., improved NCM chemistries or novel lithium-sulphur (Li-S) and lithiumair batteries (Li-Air)) as well as alternative fleet and different recycling scenarios.

Here, we go beyond previous studies by developing comprehensive global scenarios for the development of the EV fleet, battery technology (including potentially game changing chemistries such as Li-S and Li-Air) as well as recycling and seconduse of EV batteries. We assess the global material demand for light-duty EV batteries for $\mathrm{Li}, \mathrm{Ni}$, and $\mathrm{Co}$, as well as for manganese $(\mathrm{Mn})$, aluminum $(\mathrm{Al})$, copper $(\mathrm{Cu})$, graphite, and silicon (Si) (for model details, see Supplementary Fig. 1). We also relate material demands to current production capacities and known reserves and discuss key factors for reducing material requirements. The results presented are intended to inform the ongoing discussion on the transition to electric vehicles by providing a better understanding of future battery material demand and the key factors driving it.

\section{Results}

EV fleet growth. Figure 1 shows the projected EV fleet development. We base our scenarios on two scenarios of the International Energy Agency (IEA) until 2030: the Stated Policies (STEP) scenario, which incorporates existing government policies and the Sustainable Development (SD) scenario, which is compatible with the climate goals of the Paris agreement and includes also the target of reaching a 30\% global sales share for EVs by $2030^{3}$. According to these scenarios, EVs will make up $8-14 \%$ of the total light-duty vehicle fleet by 2030 , of which $89-166$ million are battery electric vehicles (BEVs) and 46-71 million are plug-in

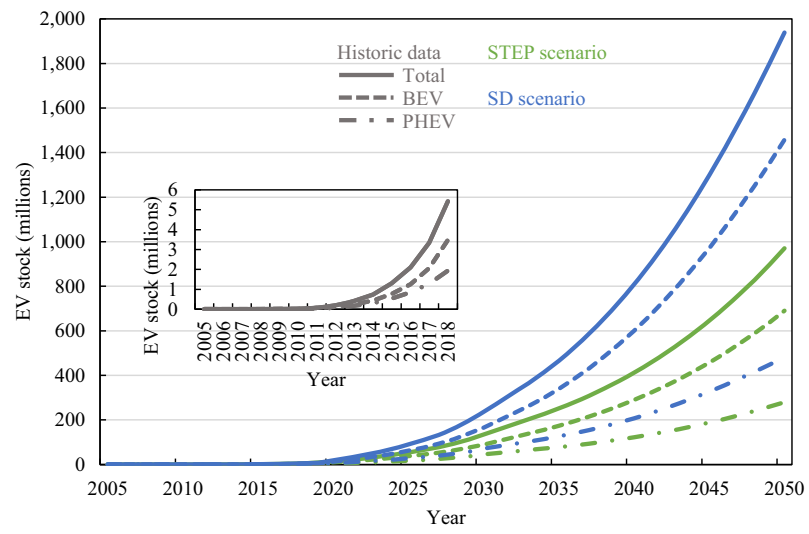

Fig. 1 Global EV stock development projected until 2050. BEV battery electric vehicle, PHEV plug-in hybrid electric vehicle, STEP scenario the Stated Policies scenario, SD scenario Sustainable Development scenario.

hybrid electric vehicles (PHEVs) ${ }^{3}$. We extend these scenarios until 2050 assuming logistic growth curves where the global fleet penetration of EVs in 2050 will be $25 \%$ in the STEP scenario and $50 \%$ in the SD scenario. This is in-line with other projections, see Supplementary Fig. 2. In the STEP scenario, the EV stock will increase by a factor of 72 from 2020-2050 to nearly 1 billion vehicles and annual EV sales will rise to 109 million vehicles (Supplementary Fig. 3). In the SD scenario, the EV stock will increase by a factor of 102 from 2020-2050 to 2 billion vehicles and annual EV sales will rise to 211 million vehicles (Supplementary Fig. 3).

Battery capacity and market shares. Figure 2 shows that in the STEP scenario $\sim 6$ TWh of battery capacity will be required annually by 2050 (and 12 TWh in the SD scenario, see Supplementary Fig. 4). The required future battery capacity depends on the development of the EV fleet as well as the required battery capacity per vehicle (we assume $66 \mathrm{kWh}$ and $12 \mathrm{kWh}$ as average capacity for BEVs and PHEVs, respectively, see Supplementary Tables 1 and 2 for details) and the battery lifespans (see Supplementary Table 3). The material requirements depend on the choice of battery chemistries used. Three battery chemistry scenarios are considered (see Fig. 2 and detailed description in methods).

The most likely NCX scenario follows the current trend of a widespread use of lithium nickel cobalt aluminum (NCA) and lithium nickel cobalt manganese (NCM) batteries (henceforth called the NCX scenario with X representing either $\mathrm{Al}$ or $\mathrm{Mn})^{17}$. Battery producers are seeking to replace costly cobalt with nickel, which has led to an evolution from NCM111 to NCM523, NCM622, and NCM811 batteries (numbers denote ratios of nickel, cobalt, and manganese) ${ }^{17}$ and NCM955 (90\% nickel, 5\% cobalt, 5\% manganese) are expected to be available by $2030^{18}$. Specific energies at the pack level assumed here range from 160 $\mathrm{Wh} / \mathrm{kg}$ for NCM111 to $202 \mathrm{Wh} / \mathrm{kg}$ for NCM955-Graphite (Si) battery for typical mid-size BEVs (Supplementary Table 4), and lifespans are assumed to increase to an average of 15 years to match vehicle lifespans (Supplementary Fig. 6) ${ }^{19}$.

The LFP scenario considers the possibility that LFP $\left(\mathrm{LiFePO}_{4}\right)$ batteries will be increasingly used for EVs in the future. The principle drawback of LFPs is their lower specific energy compared to NCA and NCM chemistries, which negatively impacts fuel economy and range of EVs. Advantages of LFPs are lower production costs due to the abundance of precursor materials, safety due to better thermal stability, and longer cycle 

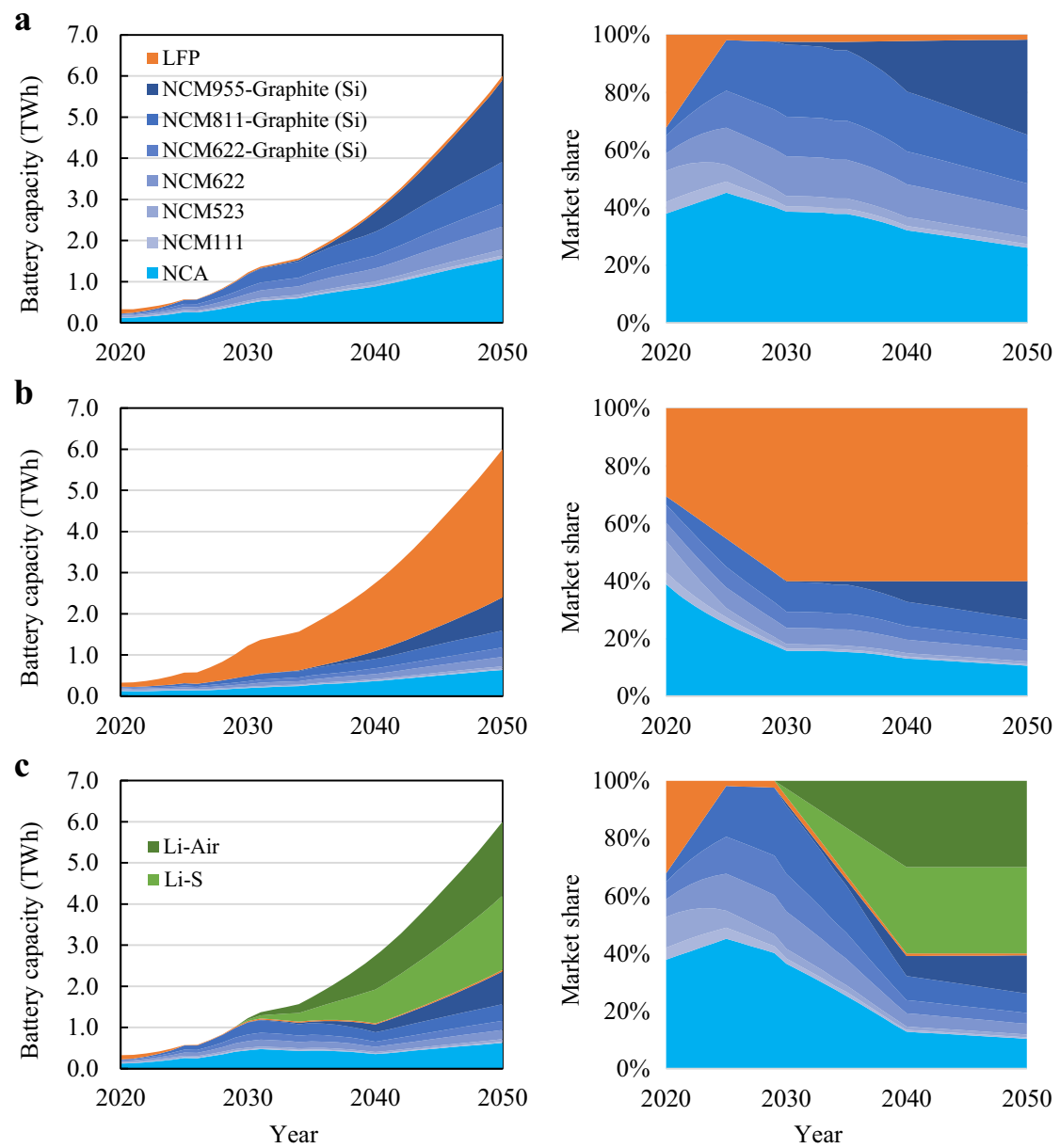

Fig. $\mathbf{2}$ Battery market shares and yearly EV battery sales until $\mathbf{2 0 5 0}$ for the fleet development in the STEP scenario. a NCX scenario. b LFP scenario. c Li-S/Air scenario. See Supplementary Fig. 4 for the Sustainable Development scenario. See Supplementary Fig. 5 for battery sales in units. LFP lithium iron phosphate battery, NCM lithium nickel cobalt manganese battery, Numbers in NCM111, NCM523, NCM622, NCM811, and NCM955 denote ratios of nickel, cobalt, and manganese. NCA lithium nickel cobalt aluminum battery, Graphite (Si) graphite anode with some fraction of silicon, Li-S lithium-sulphur battery, Li-Air lithium-air battery, TWh $10^{9} \mathrm{kWh}$.

life ${ }^{20}$. While LFP batteries have seen their main application in commercial vehicles, such as buses, there are prospects of a more widespread use of LFPs in light-duty EVs (e.g. Tesla has recently announced to equip the Chinese version of its Model 3 with LFP batteries ${ }^{21}$ ). In this scenario, we assume that LFP batteries (with a specific energy of $129 \mathrm{Wh} / \mathrm{kg}$ at pack level for typical mid-size $\mathrm{BEVs}$ and on average lifespan of 20 years $^{22}$ ) will have a market share of $60 \%$ from $2030-2050$, while the rest of the market follows the trends in the NCX scenario.

In the Li-S/Air scenario, we consider the possibility of breakthroughs in Li-metal solid state battery chemistries, specifically, Li-S and Li-Air batteries, which are seen as potential successors of $\mathrm{LIBs}^{23,24}$. Although Li-S and Li-Air batteries are still in early development and considerable challenges remain to be solved before commercialization, e.g., low cycle life and safety issues ${ }^{2,4}, \mathrm{Li}-\mathrm{S}$ batteries could reach two times and $\mathrm{Li}$-Air batteries up to three times the specific energy of current LIBs, which would likely lead to cost reductions and improved EV ranges ${ }^{23}$. Although it is highly uncertain if and when such batteries could reach market readiness, we assume that Li-S and Li-Air batteries (with specific energies of 308 and $383 \mathrm{Wh} / \mathrm{kg}$, respectively, at pack level for typical mid-size BEVs and lifespans equal to NCM batteries) enter the market in $2030^{25}$ and reach a market share of $60 \%$ by 2040 , while the rest of the market follows the trends in the NCX scenario.
Battery material demand. Figure 3 a shows the global demand for $\mathrm{Li}, \mathrm{Co}$, and $\mathrm{Ni}$ for $\mathrm{EV}$ batteries $(\mathrm{Mn}, \mathrm{Al}, \mathrm{Cu}$, graphite, and $\mathrm{Si}$ are shown in Supplementary Fig. 7a). It can be observed that higher EV deployments in the SD scenario lead to 1.7-2 times higher annual material demand than in the STEP scenario. The demand for Li is only slightly influenced by the battery chemistry scenario (although the Li-S/Air scenario requires slightly more Li due to the Li-metal anodes in Li-S and Li-Air batteries). The demand for $\mathrm{Ni}$ and $\mathrm{Co}$ is strongly influenced by the battery chemistry scenario and substantially smaller in the LFP and Li-S/Air scenarios due to the lower market shares of NCX batteries. From 2020 to 2050 in the more conservative STEP scenario, Li demand would rise by a factor of $17-21$ (from $0.036 \mathrm{Mt}$ to $0.62-0.77 \mathrm{Mt}$ ), Co by a factor of 7-17 (from $0.035 \mathrm{Mt}$ to $0.25-0.62 \mathrm{Mt}$ ), and $\mathrm{Ni}$ demand by a factor of $11-28$ (from $0.13 \mathrm{Mt}$ to $1.5-3.7 \mathrm{Mt}$ ) (for increasing factors, see Supplementary Figs. 8 and 9). Note that the demand increase for $\mathrm{Co}$ is smaller than for $\mathrm{Ni}$ due to the assumed partial replacement of Co by $\mathrm{Ni}$ in future NCM batteries. $\mathrm{Mn}$ and $\mathrm{Si}$ follow the same trend as $\mathrm{Ni}$ and $\mathrm{Co}$ in the three battery scenarios as they are also not used in LFP, Li-S, and Li-Air batteries. The demand for $\mathrm{Al}, \mathrm{Cu}$, and graphite in the LFP scenario is slightly higher than in the NCX scenario due to specific energy differences, and lower in the Li-S/ Air scenario, since Li-S and Li-Air batteries use less $\mathrm{Al}$ and $\mathrm{Cu}$ on a per kWh basis and typically do not contain graphite. 

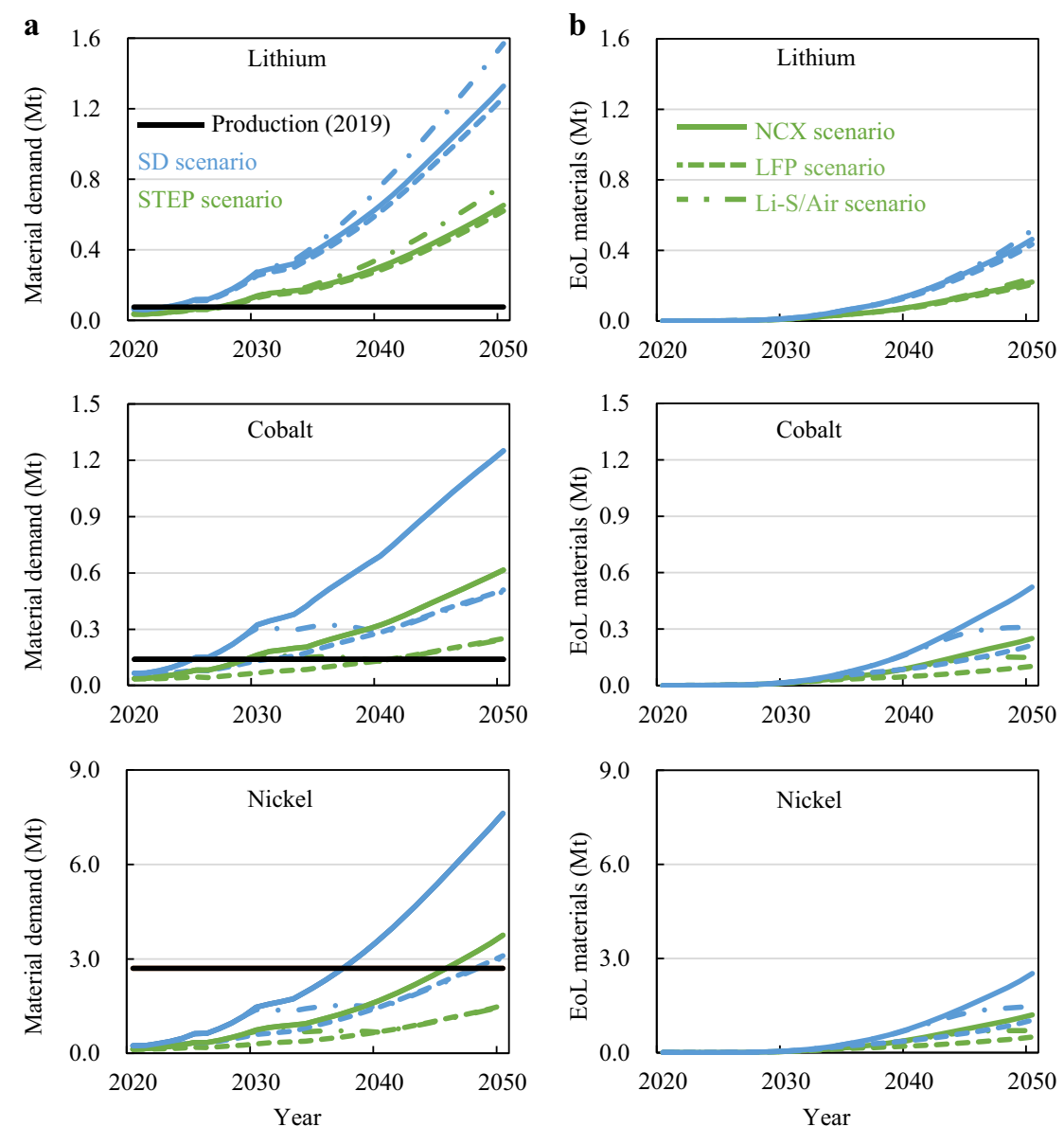

Fig. 3 Battery material flows from $\mathbf{2 0 2 0}$ to $\mathbf{2 0 5 0}$ for lithium, nickel, and cobalt in the NCX, LFP, and Li-S/Air battery scenarios. a Primary material demand. b materials in end-of-life batteries. See Supplementary Fig. 7 for other materials. STEP scenario the Stated Policies scenario, SD scenario Sustainable Development scenario, Mt million tons.
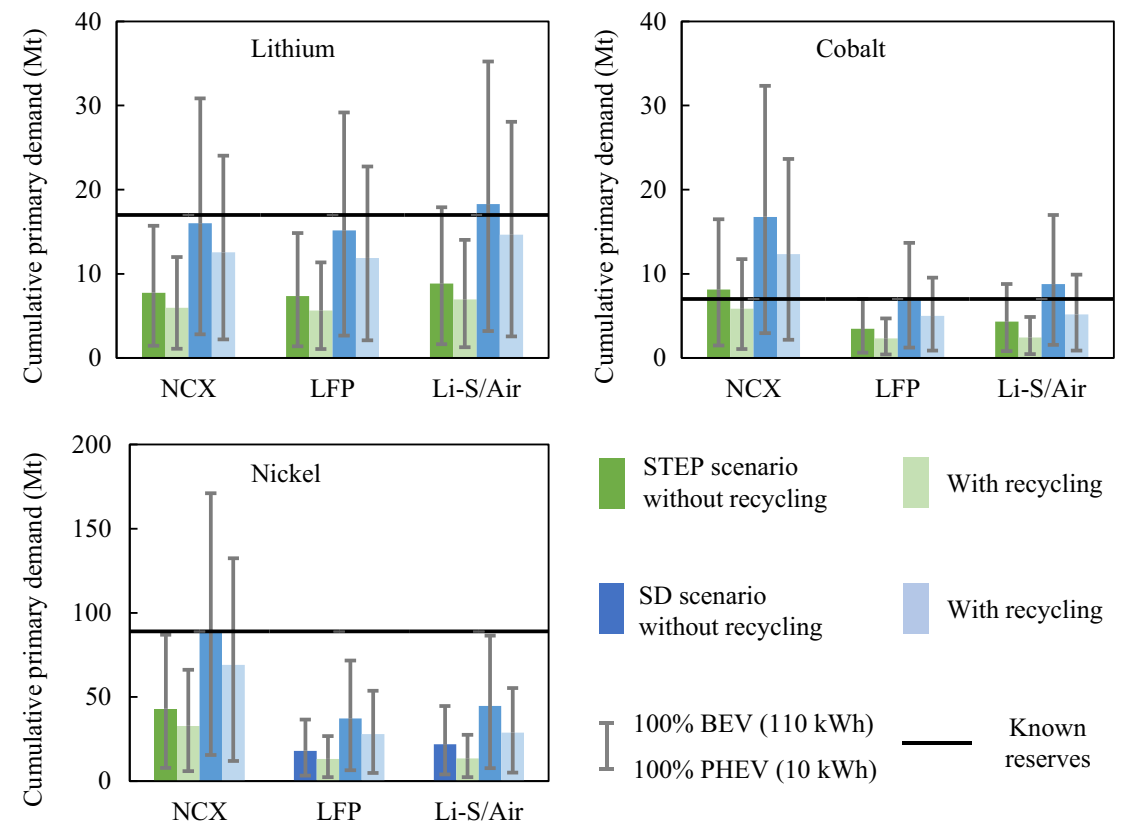

STEP scenario without recycling

SD scenario without recycling T 100\% BEV (110 kWh) $\perp \quad 100 \%$ PHEV $(10 \mathrm{kWh})$
With recycling

With recycling

Known reserves

Fig. 4 Cumulative primary material demand in 2020-2050 without recycling and with hydrometallurgical recycling. Gray error bars represent a sensitivity analysis for battery capacity considering two extreme cases (if all EVs were PHEVs with small $10 \mathrm{kWh}$ batteries or if all EVs were large SUVs with 110 kWh batteries, e.g., Tesla's Model S Long Range Plus 37 , see annual results in Supplementary Fig. 10). See Supplementary Fig. 11 for other materials. The black line represents known reserves ${ }^{32}$. STEP scenario the Stated Policies scenario, SD scenario Sustainable Development scenario, Mt million tons. 
Figure 4 shows the cumulative demand from 2020-2050. It ranges from 7.3-18.3 $\mathrm{Mt}$ for $\mathrm{Li}, 3.5-16.8 \mathrm{Mt}$ for $\mathrm{Co}$, and 18.1-88.9 $\mathrm{Mt}$ for $\mathrm{Ni}$ across fleet and battery chemistry scenarios (numbers for all materials are reported in Supplementary Table 5). The cumulative demand is twice as high in the SD scenario, and 2-2.5 times higher for Ni and Co in the NCX compared to the LFP and $\mathrm{Li}-\mathrm{S} /$ Air scenarios. Consequently, there is a factor of 4-5 between the cumulative Ni and Co demands in the SD-NCX and the STEP-LFP or STEP-Li-S/Air scenarios.

Recycling potentials. Figure $3 \mathrm{~b}$ shows the materials contained in end-of-life (EoL) batteries over time $(0.21-0.52 \mathrm{Mt}$ of $\mathrm{Li}$, $0.10-0.52 \mathrm{Mt}$ of $\mathrm{Co}$, and $0.49-2.52 \mathrm{Mt}$ of $\mathrm{Ni}$ in $9-27 \mathrm{Mt}$ EoL batteries, see Supplementary Fig. 12 for EoL battery weight, and Supplementary Figs. 13 and 14 for other materials in EoL batteries). The recovery of these materials could help to reduce primary material production ${ }^{14,26}$. Current commercial recycling technologies for EV batteries include pyrometallurgical and hydrometallurgical processing 27 . Pyrometallurgical recycling involves smelting entire batteries or, after pretreatment, battery components. Hydrometallurgical processing involves acid leaching and subsequent recovery of battery materials, e.g., through solvent extraction and precipitation. In closed-loop recycling, pyrometallurgical processing is followed by hydrometallurgical processing to convert the alloy into metal salts, as illustrated in Fig. 5. Direct recycling aims at recovering cathode materials while maintaining their chemical structures, which could be economically and environmentally advantageous ${ }^{28}$; however, it is currently still in early development stages ${ }^{29}$. In order to quantify recycling potentials, we consider three potential recycling scenarios: pyrometallurgical, hydrometallurgical, and direct recycling for NCX and LFP batteries as well as mechanical recycling for Li-S and Li-Air batteries. They differ in recovered materials and associated chemical forms (see methods and summary in Fig. 5).

We also consider the potential second-use of EoL EV batteries. The exact second-use application, the battery state-of-health, battery chemistry, and other factors determine, if and for how long second-use is possible. For the sake of simplicity and to illustrate the effect of second-use, we assume that $50 \%$ of NCX, Li-S, and Li-Air batteries before 2020 (increasing to $75 \%$ after 2020), and $100 \%$ of LFP batteries, due to their higher cycle life, experience a 10-year second-use in stationary energy storage, which is likely to be economically and environmentally beneficial $^{30}$, before finally entering recycling (Supplementary Table 6).

Figure 4 shows the cumulative battery material demand from 2020-2050 for both fleet scenarios without recycling (representing the maximum primary material demand), and with hydrometallurgical recycling of NCX and LFP batteries and mechanical recycling of Li-S and Li-Air batteries without second-use (representing the minimum primary material demand) (Supplementary Fig. 15 shows the development over time for all materials). Considering additional material losses, e.g., during collection and recycling, or material recovery delays due to second-use, would yield figures in between these bounds. This shows that battery recycling has, at best, the potential to reduce $20-23 \%$ of the cumulative material demand for Li until $2050(8 \%$ for $\mathrm{Li}$ metal), $26-44 \%$ for $\mathrm{Co}$, and $22-38 \%$ for $\mathrm{Ni}$ (see Supplementary Table 7 for other materials). The most important reason for this is the fast growth of the EV market and the time lag between the need for materials and the availability of EoL material. It should be noted that in a steady-state system, i.e., once the battery stock of a saturated EV market has been built up, secondary material shares could, theoretically, be as high as recycling efficiencies, i.e., above 90\%. Supplementary Table 8

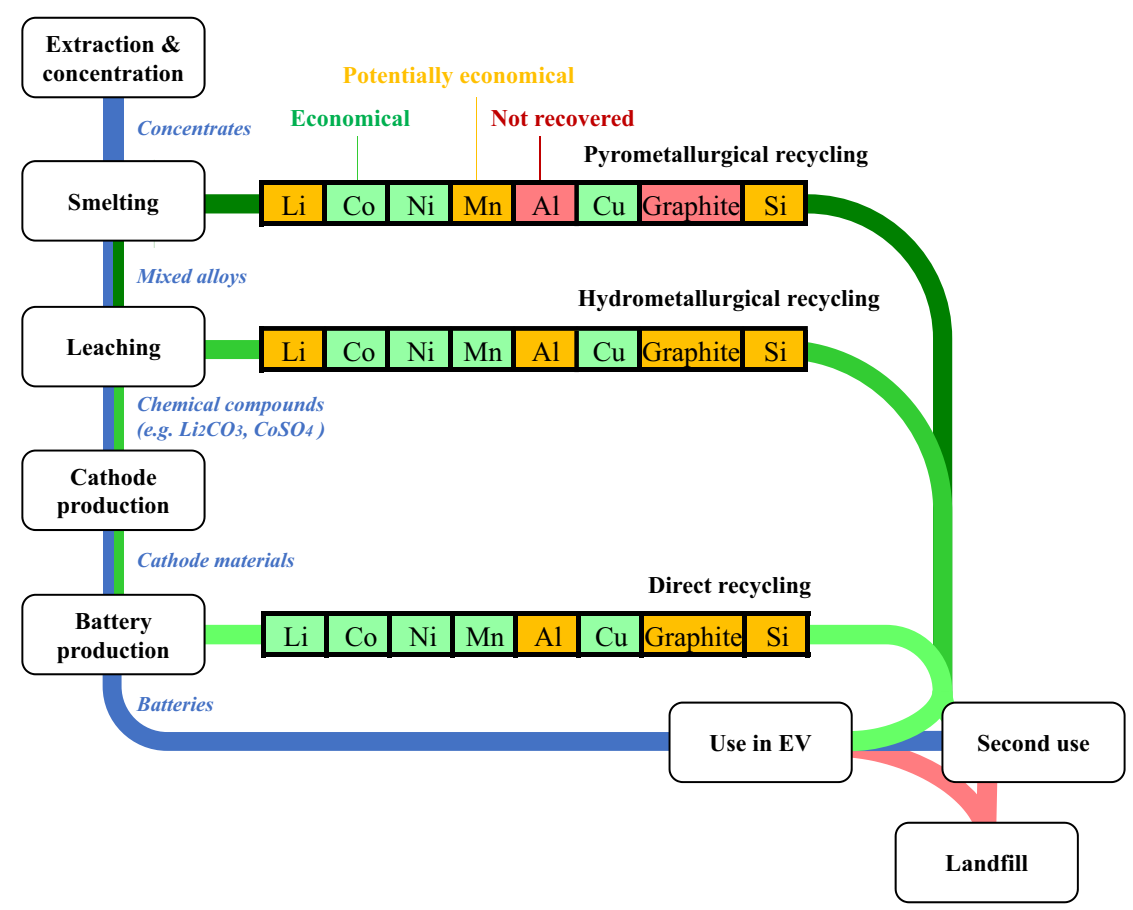

Fig. 5 Conceptual schematic showing how the three considered recycling scenarios close battery material loops and which materials are recovered. In reality not all materials go through all processing steps. For example, pyrometallurgical recycling (smelting) still requires hydrometallurgical processing (leaching) before cathode materials can be produced, while direct recycling is designed to recover cathode materials directly. In pyro- and hydrometallurgical recycling the recovery of Li may not be economical and in pyrometallurgical recycling graphite is incinerated and Al not recovered from the slag (see also methods). 


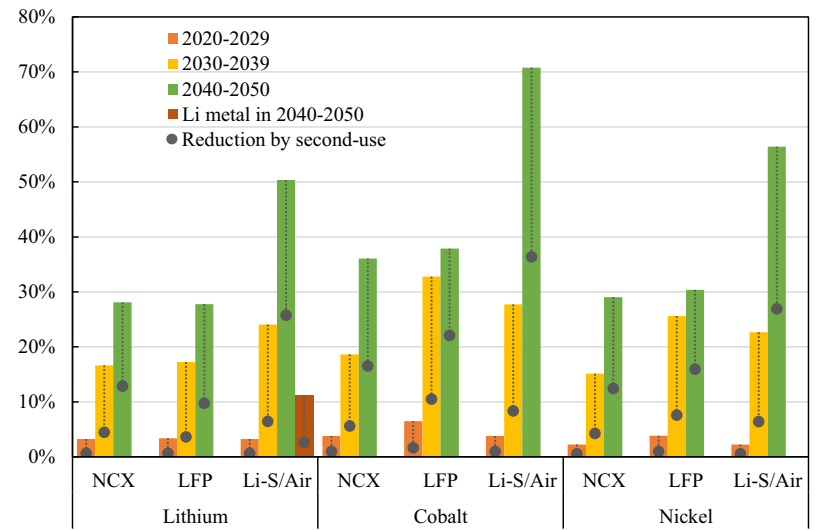

Fig. 6 Closed-loop recycling potential of battery materials in periods of 2020-2029, 2030-2039, and 2040-2050 in the STEP scenario.

Hydrometallurgical recycling is used for NCX and LFP batteries and mechanical recovery of Li metal for Li-S and Li-Air batteries. Gray dots show how second-use, which postpones the time of recycling, reduces the closed-loop recycling potentials and thus the availability of secondary materials in the coming decades. See Supplementary Table 8 for other materials.

shows the increasing potential of recycling to mitigate primary material demand over time.

Figure 6 shows the temporal evolution of the closed-loop recycling potential (CLRP), i.e., the percentage of battery material demand that can be met with secondary material from battery recycling, for the next three decades. While the CLRP is small for the current decade (below 10\%) it may reach as much as $20-71 \%$ during 2040-2050. The CLRP for Co and Ni are higher in the LFP and Li-S/Air scenarios, since LFP, Li-S, and Li-Air battery chemistries do not require these materials and the total quantity of required materials for NCX batteries is growing much slower or even stagnating for some time (see Fig. 3). Note that CLRP of $\mathrm{Li}$ and $\mathrm{Ni}$ does not exceed $31 \%$ in the NCX and LFP scenario due to the continued growth of NCX chemistries, while it surpasses $50 \%$ in the Li-S/Air scenario ( $71 \%$ for Co) in $2040-2050$ due to the higher stock of NCX batteries built up until 2030 when Li-S/ Air chemistries are introduced (see Fig. 2). In the Li-S/Air scenario, lithium compounds (e.g., $\mathrm{Li}_{2} \mathrm{CO}_{3}$ or $\mathrm{LiOH}$ ) used for cathode production of LIBs need to be distinguished from lithium metal used for Li-S and Li-Air battery anodes (see demand for each in Supplementary Fig. 16), since existing recycling technologies recover lithium as compounds, and further processing of these compounds would be necessary to produce lithium metal. Although this is technically feasible, it is unlikely to be cost competitive with primary lithium metal production from brine, which does not require the intermediate compounds production step and may work with lower-purity feedstock ${ }^{31}$. In the Li-S/Air scenario, the CLRP of lithium compounds surpasses 50\% from 2040-2050. On the other hand, the CLRP for Li metal barely reaches 10\% during 2040-2050 due to the fast growth of the Li-S and Li-Air batteries and the small historical stock.

If a significant share of batteries experience a second-use, the recovery of that material will be delayed in time and thus the CLRP will be substantially lower for the decades to come (shown by the dashed lines in Fig. 6). The CLRP of other materials follow similar patterns (see Supplementary Table 8).

\section{Discussion}

Given the magnitude of the battery material demand growth across all scenarios, global production capacity for $\mathrm{Li}, \mathrm{Co}$, and $\mathrm{Ni}$ (black lines in Fig. 3) will have to increase drastically (see
Supplementary Tables 9 and 10). For Li and Co, demand could outgrow current production capacities even before 2025. For $\mathrm{Ni}$, the situation appears to be less dramatic, although by $2040 \mathrm{EV}$ batteries alone could consume as much as the global primary $\mathrm{Ni}$ production in 2019. Other battery materials could be supplied without exceeding existing production capacities (Supplementary Tables 9 and 10), although supplies may still have to increase to meet demands from other sectors ${ }^{5,9}$. The known reserves for $\mathrm{Li}$, $\mathrm{Ni}$, and Co (black lines in Fig. 4) could be depleted before 2050 in the SD scenario and for Co also in the STEP scenario. For all other materials known reserves exceed demand from $\mathrm{EV}$ batteries until 2050 (Supplementary Table 5). In 2019 around 64\% of natural graphite and $64 \%$ of $\mathrm{Si}$ are produced in $\mathrm{China}^{32}$, which could create vulnerabilities to supply reliability ${ }^{33}$. However, synthetic graphite has begun to dominate the LIB graphite anode market (56\% market share in 2018) due to its superior performance and decreasing cost over natural graphite ${ }^{17}$. Thus, among EV battery materials $\mathrm{Co}$ and $\mathrm{Li}$, and to a lesser extent $\mathrm{Ni}$ and graphite, can be considered to be most critical concerning the upscaling of production capacities (see Supplementary Table 9), reserves and other supply risks, which confirms previous findings $5,9,10,33,34$ even without taking into consideration the potential additional demand from heavy-duty vehicles ${ }^{15}$ and other sectors ${ }^{16}$. In contrast to $\mathrm{Li}$ and $\mathrm{Ni}$, Co reserves are also geographically more concentrated and partly in conflict areas ${ }^{35}$, thus increasing potential supply risks ${ }^{5}$. Battery manufacturers are already seeking to decrease their reliance on cobalt, e.g., by lowering the Co content of NCM batteries; however, as shown in Fig. 3, an absolute decoupling is unlikely to occur in the coming decades. Shortages could also occur at a regional level, such as the access to Li and Ni for Europe ${ }^{10}$. Obviously, it is possible that the outlined supply risks change, e.g., with the discovery of new reserves ${ }^{36}$.

According to our model, lithium demand for EV batteries in $2050(0.6-1.5 \mathrm{Mt})$ could be significantly lower than projected by Weil et al. ${ }^{9}(1.1-1.7 \mathrm{Mt})$ and likely higher than projected by Hao et al..$^{15}(0.65 \mathrm{Mt})$, Deetman et al. ${ }^{16}(0.05-0.8 \mathrm{Mt})$, and Ziemann et al. ${ }^{14}(0.37-1.43 \mathrm{Mt})$. For cobalt our estimations $(0.25-1.25 \mathrm{Mt})$ are in-line with the predictions by Weil et al. ${ }^{9}(0.3-1.1 \mathrm{Mt})$ despite important differences in underlying scenarios and likely considerably higher than Deetman et al. ${ }^{16}(0.06-0.62 \mathrm{Mt})$. For nickel our estimations (1.5-7.6 Mt) partly overlap but are generally higher than those by Weil et al. ${ }^{9}(0.6-2.6)$. There are thus notable uncertainties concerning the primary material demand for EV materials related to several key factors that could be strategically addressed to mitigate supply risks. Probably the most important factor is the future required battery capacity. A sensitivity analysis is shown in Fig. 4 for two extreme battery capacity cases, i.e., if all EVs were PHEVs with small $10 \mathrm{kWh}$ batteries or if all EVs were large SUVs with $110 \mathrm{kWh}$ batteries, such as Tesla Model S Long Range Plus ${ }^{37}$. While it is unlikely that the global average EV battery capacity will be close to either end of this range, this analysis illustrates the high importance of this factor. The demand for battery capacity depends on technical factors, such as vehicle design, vehicle weight, and fuel efficiency ${ }^{38}$, and perhaps even more importantly, on socio-economic factors, such as the future EV fleet size (see also Fig. 4), consumer choices concerning the size and ranges of EVs, the cost of EV batteries and raw materials, the development of alternative transportation means and technologies (e.g., fuel cell EVs ${ }^{39}$ ), and policy.

Opportunities lie in the development of battery technology. As shown here, Li-S and Li-Air batteries would reduce the dependency on $\mathrm{Co}$, and $\mathrm{Ni}$, while offering higher energy densities. Our analysis assumes conservative, i.e., technically proven values, but if higher specific energies were to be achieved, e.g., 600 instead of $400 \mathrm{Wh} / \mathrm{kg}$ for Li-S and 1000 instead of $500 \mathrm{Wh} / \mathrm{kg}$ for Li-Air 
(see Supplementary Table 11 for material compositions), the cumulative lithium demand in the Li-S/Air scenario could be reduced by $20 \%$ and the Li metal demand by $40 \%$ (Supplementary Fig. 16). High market shares of Li-S/Air or LFP batteries or breakthroughs in post-Li batteries based on abundant elements such as sodium, magnesium, or calcium ${ }^{4}$ could lead to an absolute decoupling from lithium, cobalt and nickel (see Supplementary Figs. 17-19).

It is also uncertain whether the lifespans assumed here will be reached in practice, especially for $\mathrm{Li}-\mathrm{S}$ and $\mathrm{Li}$-Air batteries ${ }^{2}$. Lower battery lifespans could require additional battery replacements and thus lead to considerably higher material demand (see Supplementary Fig. 20 for annual demand and Table 12 for cumulative demand). On the other hand, batteries in a state-ofhealth that would typically be considered to mark their EoL (i.e., 70-80\%) may still be used by consumers who prefer to accept a shorter range over the expense of a battery replacement ${ }^{15}$ (EVs with $80 \%$ residual battery capacity could still meet daily travel requirements in $85 \%$ of cases in the US ${ }^{40}$ and widespread charging infrastructure could further support this ${ }^{41}$ ).

Truly circular EV batteries will not be available anytime soon. Over the next decades we first need to produce the EV battery stock for a large fleet, mostly from primary materials. Closed-loop recycling will gain importance, depending on EV fleet and battery chemistry developments, second-use, and other factors, such as standardization ${ }^{42}$, legislation, business models ${ }^{43}$, eco-design or design for recycling 44 , collection systems, and recycling technology 26,29 . The difference between the recycling technologies is not so much in the recycling efficiency for individual materials, but whether materials are recovered and in what chemical form and purity 9,29 . All recovered battery materials can, in principle, be refined to battery-grade. For example, in the pyrometallurgical process, lithium ends up in the slag, while in the hydrometallurgical process, lithium ends up in the solid waste from the leaching step. Both slag and solid waste could be refined to produce battery-grade lithium carbonate; however, lithium has hardly been recovered so far as the lithium price did not enable a cost-effective recovery ${ }^{9,45}$. The most economically and environmentally promising technology for closed-loop recycling, although currently largely unproven outside of the lab, is direct recycling, which could recover cathode material "as is" without intermediate smelting or leaching step (Fig. 5). Challenges for direct recycling include the development of sorting processes that can separate cathode powder from different battery chemistries, relithiation and upgrading processes for cathode chemistries that have become obsolete and further standardization of batteries to support effective recycling ${ }^{46}$.

The success of the transition to electric vehicles will depend partly on whether the material supply can keep up with the growth of the sector in a sustainable way and without damaging the reputation of EVs. Science-based sustainability assessments, such as life cycle assessment, should guide the selection of alternative battery chemistries and raw materials to avoid unfavorable burden-shifts. The global demand scenarios presented here also provide a basis to assess the global economic, environmental, and social impacts related to EVs and batteries from a lifecycle perspective.

\section{Methods}

Model overview. We develop a dynamic material flow analysis (MFA) model, which is a frequently used approach to analyze material stocks and flows ${ }^{47}$. Our stock-driven MFA model estimates the future material demand for EV batteries as well as EoL materials available for recycling. It consists of an EV layer, a battery layer, and a material layer, and considers key technical and socio-economic parameters in three layers (Supplementary Fig. 1). The EV layer models the future EV stock (fleet) development until 2050 as well as required battery capacity. The $\mathrm{EV}$ stock then determines the battery stock, which in turn determines the battery inflows and, considering their lifespan distributions (see Supplementary Method 1) the outflow of EoL batteries (see Supplementary Method 2). The battery layer considers future battery chemistry developments and market shares. The material layer models material compositions of battery chemistries using the $\mathrm{BatPaC}$ model $^{48}$. The fate of EoL batteries is modelled considering three recycling scenarios and a second-use scenario and these determine the material availability for closedloop recycling. The model layers and parameters are described in the following.

EV fleet scenarios and required battery capacity. Projections for the development of the EV fleet vary, but most studies project a substantial penetration of EVs in the light-duty vehicle (LDV) market in the future (Supplementary Fig. 2). We use two EV fleet development scenarios of the IEA until 2030: the stated policies (STEP) scenario and the sustainable development (SD) scenario ${ }^{3}$ (and estimate the annual EV stock based on the equivalent IEA 2019 scenarios ${ }^{49}$, see Supplementary Fig. 21). We then extrapolate the EV fleet penetration until 2050 using a logistic model (see Supplementary Figs. 22) ${ }^{50}$ based on a target penetration of EVs in the LDV market in 2050 of $25 \%$ in the STEP scenario and $50 \%$ in the SD scenario (which is in-line with other EV forecasts, as shown in Supplementary Fig. 2). To estimate future EV fleet until 2050, we further assume a linear growth for global LDV stock from 503 million vehicles in 2019 to 3.9 billion vehicles in 2050, which is in-line with projection by Fuel Freedom Foundation ${ }^{51}$. Global predictions of the future development of BEV and PHEV shares were not available. To estimate future shares of BEVs and PHEVs in the EV stock, we assumed that the global share of BEVs increases in the same way as the US BEV share projected by the US Energy Information Administration ${ }^{52}$, but starting from the 2030 levels of the STEP and SD scenarios (i.e., from $66 \%$ in 2030 to $71 \%$ in 2050 in STEP scenario and $70 \%$ in 2030 to $75 \%$ in 2050 in SD scenario, see Supplementary Fig. 23).

We classify EVs models into three market segments (small, mid-size, and large cars for both BEVs and PHEVs) based on vehicle size classes used in the Fuel Economy Guide by EPA (see Supplementary Table 13) ${ }^{53}$, and collect global sales of each EV model from the Marklines database ${ }^{54}$. We use the distribution of cumulative sales until 2019 to represent EV sales market shares among small, midsize, and large segments (Supplementary Figures 24 and 25). As a result, we obtained 19, 48, and 34\% for small, mid-size, and large cars for BEVs, and 23, 45, and $32 \%$ for PHEVs. We assume EVs sales market share remain constant; however, a sensitivity analysis is conducted to obtain the upper and lower bounds for material requirements if all vehicles were large BEV or small PHEV (see sensitivity analysis)

We collect range, fuel economy, and motor power of each EV model from Advanced Fuels Data Center of US DOE ${ }^{55}$, and calculate sales-weighted average range, fuel economy, and motor power for three market segments for both BEVs and PHEVs (Supplementary Tables 1 and 2). By assuming 85\% available battery capacity for driving EVs based on BatPaC model ${ }^{48}$, we obtain 33,66 , and $100 \mathrm{kWh}$ for small, mid-size, and large BEVs (see Supplementary Table 2 for PHEV).

Passenger car lifespans have been found to vary from 9 to 23 years among countries with average lifespan of around 15 years ${ }^{56}$. EV lifespan depends on consumer behavior, technical lifespan (see next section), and other factors. Here we use a Weibull distribution ${ }^{57}$ to model the EV lifespan assuming the minimum, maximum, and most likely lifespans of EVs to be 1, 20, and 15 years, respectively (see Supplementary Fig. 6). We do not consider battery remanufacture and reuse from one EV to another EV due to performance degradation, technical compatibility, and consumer acceptance.

Battery chemistry scenarios and market shares. Although various EV battery chemistries have been developed for EVs to decrease cost and improve performance, current major battery roadmaps in $\mathrm{US}^{58}, \mathrm{EU}^{25}$, Germany ${ }^{59}$, and China ${ }^{60}$ focus on cathode material development considering high-energy NCM (transition to low cobalt and high nickel content) and NCA based chemistries to be the likely next generation of LIBs for EVs in next decade, as well as anode material development considering adding Si to graphite anode. This is also reflected in commercial activities by battery producers (e.g., LG Chem or CATL) ${ }^{61}$ and market share projections until 2030 by Avicenne Energy ${ }^{17}$, which we use in this study. We assume that NCM batteries continue to decrease cobalt content and increase nickel content after 2030 and compile the NCX scenario (where X represents either Al or Mn) until 2050 (including eight chemistries, see Supplementary Table 14). In the NCX scenario, we assume that NCM955 (90\% nickel, 5\% cobalt, 5\% manganese) are introduced in $2030^{18}$, and gradually replace other previous chemistries proportionally to reach a market share of one third by 2050 (i.e., market shares of NCM111, NCM523, NCM622, NCM622-Graphite (Si), NCM811-Graphite (Si), NCA, and LFP batteries are assumed to decrease proportionally after 2030, see Fig. 2b).

Future battery chemistry developments after 2030 are uncertain, but conceivable battery chemistries, in addition to NCM and NCA batteries, include already existing LFP batteries ${ }^{21,62}$, as well high-capacity Li-metal solid state batteries, such as Li-S and Li-Air ${ }^{23,25}$. We therefore include two additional what-if scenarios next to the NCX scenario: an LFP scenario and a Li-S/Air scenario. In the LFP scenario, the market share of LFP chemistry is assumed to increase linearly from around $30 \%$ in 2019 to $60 \%$ by 2030 and remain at this level until 2050 (i.e., other batteries lost market share proportionally compared to the NCX scenario, see Fig. 2b). In the Li-S/Li-Air scenario, we assume $\mathrm{Li}-\mathrm{S}$ and $\mathrm{Li}$-Air batteries to be 
commercially available in 2030 based on commercial plans of Li-S by OXIS Energy ${ }^{63}$ and Li-Air by Samsung Electronics ${ }^{64}$ and then they obtain linearly increasing market share to $30 \%$ each (totally $60 \%$ ) by 2040 , and maintain this share until 2050 (NCA and NCM batteries supply the rest of the market by historical proportions, see Fig. 2b).

The real-world lifespan of batteries is influenced by additional factors not modelled here, such as ambient temperature, depth and rates of charge and discharge, driving cycles ${ }^{65}$. We use the technical lifespan of batteries. Before 2020, we assume that batteries are likely to last 8 years (based on the battery warranty of EV manufactures) $)^{66}$, which is shorter than EV lifespan (Supplementary Table 15). We assume a $50 \%$ battery replacement rate for EVs before 2020 (i.e., one EV requires 1.5 battery packs on average). Battery research agendas in the US ${ }^{58}, \mathrm{EU}^{25}$, and China ${ }^{60}$ include targets to increase the lifespan of batteries, which is why we assume that after 2020 batteries will have the same lifespan distributions as EVs and no replacement of batteries is required (Supplementary Table 16). Note that we assume higher lifespans for LFP batteries (20 years on average) (Supplementary Fig. 6), which leads to a higher second-use potential than for the other battery types.

Battery material compositions. The battery material compositions are calculated by using the $\mathrm{BatPaC}$ model version $3.1^{48}$ as a function of the $2 \mathrm{EV}$ types (BEVs or PHEVs), the 3 EV market segments (small, mid-size, and large cars), and the 8 battery chemistries (LFP, NCA, NCM11, NCM523, NCM622, NCM622-Graphite (Si), NCM811-Graphite (Si), NCM955-Graphite (Si)), which yields 48 unique battery chemistries. The input parameters include the EV range, fuel economy, and motor power, which determine the required capacity of each EV type and market segment (Supplementary Tables 1 and 2), and battery chemistry and other parameters (like the design of battery modules and cell components) for which we use the default values in the $\mathrm{BatPaC}$ model. To calculate the material compositions of battery chemistries that do not exist in BatPaC (i.e., NCM523, NCM622-Graphite (Si), NCM811-Graphite (Si), NCM955-Graphite (Si)), we use the closest matching battery chemistry in $\mathrm{BatPaC}$ as a basis and then adapt technical parameters, such as $\mathrm{Ni}, \mathrm{Co}, \mathrm{Mn}$ contents in the positive active material and $\mathrm{Si}$ and graphite contents in the negative active material, by stoichiometry, as well as active material capacities (Supplementary Tables 17-19) and open circuit voltage (see Supplementary Table 20 and Note 1 ).

For Li-S and Li-Air chemistries, we performed a literature review on the specific energy and material compositions of Li-S and Li-Air cells (Supplementary Tables 21 and 22), and then scale these linearly to meet required battery capacities for each EV type and market segment (Supplementary Note 2). The pack components of Li-S and Li-Air are assumed to be based on the pack configurations of NCA chemistry (i.e., the same weight ratio between cell components and pack components). Supplementary Table 23 shows the material compositions used in this paper.

Recycling scenarios. Recycling of EoL batteries provides a secondary supply of materials. Here we assume $100 \%$ collection rates and explore the effects of recycling efficiencies of three recycling scenarios (see Supplementary Table 24) on primary material demand, including recovered quantities and some discussion of recycled material qualities. The primary material demand when there is no collection and recycling of EoL batteries is captured by the "without recycling" scenario (Fig. 4). Currently commercialized recycling technologies include pyrometallurgical (pyro) and hydrometallurgical (hydro) recycling. Direct recycling is under development for cathode-to-cathode recycling. For NCX and LFP batteries, pyro, hydro, and direct recycling are assumed in the three recycling scenarios, respectively, while mechanical recycling is assumed for Li-S and Li-Air batteries in all three scenarios. Recycling technologies differ in recycled materials, chemical forms, recovery efficiencies, and economic prospects $46,67,68$ (Fig. 5).

The pyrometallurgical recycling scenario we consider is in fact a hybrid pyro and hydro process. After feeding disassembled battery modules and/or cells to the smelter, graphite is burnt off, aluminum and lithium end up in the slag, and nickel, cobalt, and copper end up in a matte. After leaching of the matte, copper ion is recovered as copper metal through electrowinning, while the nickel and cobalt ions are recovered as battery-grade nickel and cobalt compounds through solvent extraction or precipitation. The lithium in the slag can be refined to produce battery-grade lithium compounds, but it is only economical when lithium price is high and recycling at scale. Technically, aluminum in the slag can also be recovered, but it is not economical and not considered by pyro recycling companies (the slag may be used, e.g., as aggregate in construction material).

The hydrometallurgical recycling scenario starts with shredding disassembled modules and/or cells. The shred then goes through a series of physical separation steps to sort the materials into cathode powder, anode powder, and mixed aluminum and copper scraps. Depending on the scrap metal prices, the mixed aluminum and copper scraps may be further sorted into aluminum scraps and copper scraps. The copper scraps can be incorporated back into the battery supply chain with minimal processing (i.e., remelting). The closed-loop recycling of aluminum is more challenging as the recovered aluminum scraps are a mixture of different aluminum alloys (e.g., from current collector and casing) and $\mathrm{Al}$ is, therefore, typically downcycled. Closed-loop recycling of aluminum would require separating the aluminum alloy before or during the recycling process, which may or may not be economical ${ }^{69}$. The cathode powder is subsequently leached with acid, where nickel, cobalt, and manganese leach out as ions, and recovered as battery-grade compounds after solvent extraction and precipitation. Lithium ends up in the solid waste, which can also be used as construction materials. Similar to pyro recycling, lithium in the solid waste can be recovered as battery-grade compound, but the economic viability depends on the lithium price. The anode powder recovered through hydro, which can be a blend of graphite and silicon, is not battery-grade. Although they can be refined to battery-grade, at present the economic viability is unclear.

The direct recycling scenario is the same as hydro except for cathode powder recycling. In the direct process, the cathode powder is recovered and then regenerated by reacting with a lithium source (relithiation and upgrading). Lithium, nickel, cobalt, and manganese are therefore recovered as one batterygrade compound. Since lithium refining is not needed here as with pyro and hydro, lithium recovery in direct process is economical at least from a lab-scale perspective.

The material recovery efficiencies for pyro, hydro, and direct are taken from the EverBatt ${ }^{67}$ model developed at Argonne National Laboratory (Supplementary Table 24). As for mechanical recycling of Li-S and Li-Air batteries, we assume that only metallic lithium is recovered from the process. The material recovery efficiency of metallic lithium is assumed to be $90 \%$, and the recovery is considered economical due to the relatively simple process and high value of recovered lithium metal.

Second-use/use scenarios. EoL EV batteries may experience a second-use for less demanding applications (non-automotive), such as stationary energy storage, as they often have remaining capacities of around $70-80 \%$ of their original capacity ${ }^{70,71}$. Technical barriers exist (e.g., the performance of repurposed batteries) and economic uncertainty (the cost of repurposing including disassembly, testing, and repackaging) that depend on the battery chemistry, state-of-health, and the intended second-use application ${ }^{72,73}$. Here we distinguish the second-use rates of LFP and other chemistries due to the long cycle life $\mathrm{f}^{20}$ and the reduced chance of cascading failure of $\mathrm{LFP}^{74}$. LFP batteries are assumed to have a $100 \%$ second-use rate. For the rest of the battery chemistries, we assume a $50 \%$ second-use rate before 2020, rising to $75 \%$ during 2020-2050 because of improved technical lifespan of EV batteries (see Supplementary Table 6). The second-use applications vary from home use to electricity system integration, resulting in the second-use lifespan varying from 6 to 30 years $^{75}$. We assume a typical 10 -year second-use lifespan ${ }^{71}$ to explore the effects of second-use on the availability of materials for recycling. Note here the second-use assumes $100 \%$ reuse of battery modules, while pack components enter recycling directly.

Sensitivity analysis. The effect of important factors such as EV fleet size and battery chemistry are investigated in dedicated scenarios. In addition, we perform sensitivity analysis for (a) battery lifespan, (b) required battery capacity per vehicle, (c) the market penetration of Co- and Ni-free battery chemistries, and (d) the future specific energies of Li-S and Li-Air chemistries (for which conservative numbers were assumed).

(a) Battery lifespan has an important effect on the number of batteries required for EVs. We perform a sensitivity analysis of the effect of lower battery lifespans on battery material demand by assuming that also after 2020 one EV needs 1.5 batteries on average (results in Supplementary Fig. 20).

(b) Future market shares of BEVs and PHEVs and EV battery capacity are also key for determining the quantity of required materials. While battery capacity is driven by many factors like EV range, fuel economy, and powertrain configurations, we perform a sensitivity analysis on two extreme situations, $100 \%$ BEV with $110 \mathrm{kWh}$ capacity (large SUVs such as Tesla Model S Long Range Plus ${ }^{37}$, see Supplementary Table 25 for material compositions) and $100 \%$ PHEV with $10 \mathrm{kWh}$ capacity (see Supplementary Table 26 for material compositions), to explore the bounds of future material demand (see associated cumulative material requirements in Fig. 4 and Supplementary Fig. 11, see annual results in Supplementary Fig. 10).

(c) Similarly, we also explore the effects of $100 \%$ market share of LFP in the LFP scenario and 100\% market share of Li-S and Li-Air in the Li-S/Air scenario (see Supplementary Fig. 17 and associated material requirements in Supplementary Figs. 18 and 19, respectively).

(d) The improvement of material performance of battery chemistry, especially specific energy (stored energy per weight), may reduce material demand dramatically. Here we chose Li-S and Li-Air chemistries in the Li-S/Air scenario to perform a sensitivity analysis of the potential specific energy improvement from $400 \mathrm{Wh} / \mathrm{kg}$ to $600 \mathrm{Wh} / \mathrm{kg}$ for Li-S and from $500 \mathrm{Wh} / \mathrm{kg}$ to $1000 \mathrm{Wh} / \mathrm{kg}$ for Li-Air (values based on review of industrial and lab-scale achievements, see Supplementary Table 11 for material compositions and associated material requirements in Supplementary Fig. 16).

\section{Data availability}

The authors declare that the data used as model inputs supporting the findings of this study are available within the paper and its Supplementary Information files. Data and 
model are also provided as Excel files to facilitate further research (https://doi.org/ 10.6084/m9.figshare.13042001.v1).

Received: 30 September 2020; Accepted: 23 October 2020; Published online: 09 December 2020

\section{References}

1. Knobloch, F. et al. Net emission reductions from electric cars and heat pumps in 59 world regions over time. Nat. Sustain. 3, 437-447 (2020).

2. Deng, J., Bae, C., Denlinger, A. \& Miller, T. Electric vehicles batteries: requirements and challenges. Joule 4, 511-515 (2020).

3. Global EV Outlook 2020: Entering the decade of electric drive? (International Energy Agency, 2020). https://www.iea.org/reports/global-ev-outlook-2020.

4. Ponrouch, A. \& Rosa Palacín, M. Post-Li batteries: promises and challenges. Philos. Trans. R. Soc. A 377, 20180297 (2019).

5. Olivetti, E. A., Ceder, G., Gaustad, G. G. \& Fu, X. Lithium-ion battery supply chain considerations: analysis of potential bottlenecks in critical metals. Joule 1, 229-243 (2017).

6. Van den Brink, S., Kleijn, R., Sprecher, B. \& Tukker, A. Identifying supply risks by mapping the cobalt supply chain. Resour. Conserv. Recycl. 156, 104743 (2020).

7. Banza Lubaba Nkulu, C. et al. Sustainability of artisanal mining of cobalt in DR Congo. Nat. Sustain. 1, 495-504 (2018).

8. Thies, C., Kieckhäfer, K., Spengler, T. S. \& Sodhi, M. S. Assessment of social sustainability hotspots in the supply chain of lithium-ion batteries. Procedia CIRP 80, 292-297 (2019).

9. Weil, M., Ziemann, S. \& Peters, J. The Issue of Metal Resources in Li-Ion Batteries for Electric Vehicles. in Behaviour of Lithium-Ion Batteries in Electric Vehicles: Battery Health, Performance, Safety, and Cost (eds Pistoia, G. \& Liaw, B.) 59-74 (Springer, 2018).

10. Simon, B., Ziemann, S. \& Weil, M. Potential metal requirement of active materials in lithium-ion battery cells of electric vehicles and its impact on reserves: Focus on Europe. Resour. Conserv. Recycl. 104, 300-310 (2015).

11. Richa, K., Babbitt, C. W., Gaustad, G. \& Wang, X. A future perspective on lithium-ion battery waste flows from electric vehicles. Resour. Conserv. Recycl. 83, 63-76 (2014).

12. Gaines, L. \& Nelson, P. Lithium-ion batteries: possible materials issues. in 13th international battery materials recycling seminar and exhibit, Broward County Convention Center, Fort Lauderdale, Florida (2009).

13. Song, J. et al. Material flow analysis on critical raw materials of lithium-ion batteries in China. J. Clean Prod. 215, 570-581 (2019).

14. Ziemann, S., Müller, D. B., Schebek, L. \& Weil, M. Modeling the potential impact of lithium recycling from EV batteries on lithium demand: a dynamic MFA approach. Resour. Conserv. Recycl. 133, 76-85 (2018).

15. Hao, H. et al. Impact of transport electrification on critical metal sustainability with a focus on the heavy-duty segment. Nat. Commun. 10, 5398 (2019).

16. Deetman, S., Pauliuk, S., van Vuuren, D. P., van der Voet, E. \& Tukker, A. Scenarios for demand growth of metals in electricity generation technologies, cars, and electronic appliances. Environ. Sci. Technol. 52, 4950-4959 (2018).

17. The Rechargeable Battery Market and Main Trends 2018-2030 (Avicenne Energy, 2019). https://www.bpifrance.fr/content/download/76854/831358/file/ 02\%20-\%20Presentation\%20Avicenne\%20-\%20Christophe\%20Pillot\%20-\% 2028\%20Mai\%202019.pdf.

18. 2019 Vehicle Technologies Office Annual Merit Review Report (U.S. Department of Energy, 2020). https://www.osti.gov/servlets/purl/1601333.

19. SET-Plan ACTION n'7-Declaration of Intent "Become competitive in the global battery sector to drive e-mobility forward". (European Commission, 2016). https://setis.ec.europa.eu/system/files/integrated_set-plan/ action7 declaration of intent 0.pdf.

20. Nitta, N., Wu, F., Lee, J. T. \& Yushin, G. Li-ion battery materials: present and future. Mater. Today 18, 252-264 (2015).

21. Tesla wins China approval to build Model 3 vehicles with LFP batteries: ministry (Reuters, 2020). https://www.reuters.com/article/us-tesla-chinaelectric-batteries/tesla-wins-china-approval-to-build-model-3-vehicles-withlfp-batteries-ministry-idUSKBN23I0VT.

22. CATL batteries energise Powin's new 'long duration, long life' Li-Ion systems (Energy Storage News, 2020). https://www.energy-storage.news/news/catlbatteries-energise-powins-new-long-duration-long-life-li-ion-systems.

23. Cano, Z. P. et al. Batteries and fuel cells for emerging electric vehicle markets. Nat. Energy 3, 279-289 (2018).

24. Benveniste, G., Rallo, H., Casals, L. C., Merino, A. \& Amante, B. Comparison of the state of lithium-sulphur and lithium-ion batteries applied to electromobility. J. Environ. Manag. 226, 1-12 (2018).
25. Inventing the sustainable batteries of the future (BATTERY 2030+, 2020). https://battery2030.eu/digitalAssets/816/c_816048-1_1-k_roadmap-27-march. pdf.

26. Mayyas, A., Steward, D. \& Mann, M. The case for recycling: overview and challenges in the material supply chain for automotive li-ion batteries. Sustain. Mater. Technol. 19, e00087 (2019).

27. Gaines, L. Lithium-ion battery recycling processes: research towards a sustainable course. Sustain. Mater. Technol. 17, e00068 (2018).

28. Ciez, R. E. \& Whitacre, J. F. Examining different recycling processes for lithium-ion batteries. Nat. Sustain. 2, 148-156 (2019).

29. Harper, G. et al. Recycling lithium-ion batteries from electric vehicles. Nature 575, 75-86 (2019).

30. Richa, K., Babbitt, C. W., Nenadic, N. G. \& Gaustad, G. Environmental tradeoffs across cascading lithium-ion battery life cycles. Int. J. Life Cycle Assess. 22, 66-81 (2015).

31. Lang, J. et al. High-purity electrolytic lithium obtained from low-purity sources using solid electrolyte. Nat. Sustain. 3, 386-390 (2020).

32. Mineral Commodity Summaries 2020 (USGS, 2020). https://pubs.usgs.gov/ periodicals/mcs2020/mcs2020.pdf.

33. Study on Critical Raw Materials at EU Level (Oakdene Hollins and Fraunhofe ISI, 2013). http://ec.europa.eu/DocsRoom/documents/5605/attachments/1/ translations/en/renditions/native.

34. Helbig, C., Bradshaw, A. M., Wietschel, L., Thorenz, A. \& Tuma, A. Supply risks associated with lithium-ion battery materials. J. Clean Prod. 172, 274-286 (2018).

35. Alves Dias, P., Blagoeva, D., Pavel, C. \& Arvanitidis, N. Cobalt: demandsupply balances in the transition to electric mobility. Publications Office of the European Union 10, 97710 (2018)

36. Prior, T., Giurco, D., Mudd, G., Mason, L. \& Behrisch, J. Resource depletion peak minerals and the implications for sustainable resource management. Glob. Environ. Change 22, 577-587 (2012).

37. Tesla is working on new $\sim 110 \mathrm{kWh}$ battery pack for more than 400 miles of range (Electrek, 2020). https://electrek.co/2020/02/19/tesla-110-kwh-batterypack-400-miles-range/

38. Delogu, M., Zanchi, L., Dattilo, C. A. \& Pierini, M. Innovative composites and hybrid materials for electric vehicles lightweight design in a sustainability perspective. Mater. Today Commun. 13, 192-209 (2017).

39. Eberle, U. \& Von Helmolt, R. Sustainable transportation based on electric vehicle concepts: a brief overview. Energy Environ. Sci. 3, 689-699 (2010)

40. Saxena, S., Le Floch, C., MacDonald, J. \& Moura, S. Quantifying EV battery end-of-life through analysis of travel needs with vehicle powertrain models. $J$. Power Sources 282, 265-276 (2015).

41. Neubauer, J. \& Wood, E. The impact of range anxiety and home, workplace, and public charging infrastructure on simulated battery electric vehicle lifetime utility. J. Power Sources 257, 12-20 (2014).

42. Brown, S., Pyke, D. \& Steenhof, P. Electric vehicles: the role and importance of standards in an emerging market. Energy Policy 38, 3797-3806 (2010).

43. Prior, T., Wäger, P. A., Stamp, A., Widmer, R. \& Giurco, D. Sustainable governance of scarce metals: the case of lithium. Sci. Total Environ. 461-462, 785-791 (2013)

44. Zwolinski, P. \& Tichkiewitch, S. An agile model for the eco-design of electric vehicle Li-ion batteries. CIRP Ann. 68, 161-164 (2019).

45. Meng, F., McNeice, J., Zadeh, S. S. \& Ghahreman, A. Review of lithium production and recovery from minerals, brines, and lithium-ion batteries. Miner. Process Extr. Metall. Rev. https://doi.org/10.1080/08827508.2019.1668387 (2019).

46. Chen, M. et al. Recycling end-of-life electric vehicle lithium-ion batteries. Joule 3, 2622-2646 (2019).

47. Müller, D. B. Stock dynamics for forecasting material flows-Case study for housing in The Netherlands. Ecol. Econ. 59, 142-156 (2006).

48. Nelson, P., Ahmed, S., Gallagher, K. \& Dees, D. Modeling the Performance and Cost of Lithium-Ion Batteries for Electric-Drive Vehicles, Third Edition (Argonne National Lab, 2019). https://www.osti.gov/servlets/purl/1503280.

49. Global EV Outlook 2019: Scaling-up the transition to electric mobility (International Energy Agency, 2019). https://www.iea.org/reports/global-evoutlook-2019.

50. Al-Alawi, B. M. \& Bradley, T. H. Review of hybrid, plug-in hybrid, and electric vehicle market modeling studies. Renew. Sust. Energ. Rev. 21, 190-203 (2013).

51. Sitty, G. \& Taft, N. What Will the Global Light-Duty Vehicle Fleet Look like through 2050? (Fuel Freedom Foundation, 2016). https://www.fuelfreedom. org/wp-content/uploads/What-will-the-Global-Light-Duty-Vehicle-Fleetlook-like-through-2050_FINAL_Dec2016.pdf.

52. Annual energy outlook 2020 with projections to 2050: light-duty vehicle sales by technology type (U.S. Energy Information Administration, 2020). https://www. eia.gov/outlooks/aeo/data/browser/\#/?id=48-AEO2020\&sourcekey $=0$.

53. Vehicle Size Classes Used in the Fuel Economy Guide (EPA, 2019). https:// www.fueleconomy.gov/feg/findacarhelp.shtml\#epaSizeClass. 
54. Connect to the global automotive industry (Marklines database, 2020). https:// www.marklines.com/en/.

55. Find Electric Vehicle Models (US Department of Energy, 2019). https://www. energy.gov/eere/electricvehicles/find-electric-vehicle-models.

56. Oguchi, M. \& Fuse, M. Regional and longitudinal estimation of product lifespan distribution: a case study for automobiles and a simplified estimation method. Environ. Sci. Technol. 49, 1738-1743 (2015).

57. Zhang, L., Yuan, Z. \& Bi, J. Predicting future quantities of obsolete household appliances in Nanjing by a stock-based model. Resour. Conserv. Recycl. 55, 1087-1094 (2011).

58. Electrochemical energy storage technical team roadmap (USDRIVE, 2017) https://www.energy.gov/sites/prod/files/2017/11/f39/EESTT\%20roadmap\% 202017-10-16\%20Final.pdf.

59. Roadmap for an integrated cell and battery production in Germany (The Federal Government's Joint Office for Electric Mobility, 2016). http:// nationale-plattform-elektromobilitaet.de/fileadmin/user_upload/Redaktion/ Publikationen/AG2_Roadmap_Zellfertigung_eng_bf.pdf.

60. Chen, K., Zhao, F., Hao, H. \& Liu, Z. Selection of lithium-ion battery technologies for electric vehicles under China's new energy vehicle credit regulation. Energy Procedia 158, 3038-3044 (2019).

61. NCM 811: The future of electric car batteries? (INSIDEEVs, 2018). https:// insideevs.com/news/341168/ncm-811-the-future-of-electric-car-batteries/.

62. LFP chemistry is emerging as the future of batteries (Clean Future, 2020). http://www.cleanfuture.co.in/2020/07/09/lfp-chemistry-future-of-batteries/.

63. It's safer with OXIS lithium sulfur rechargeable batteries (OXIS Energy, 2016). http://oxisenergy.com/wp-content/uploads/2016/05/oxis-brochure.pdf.

64. Samsung's lithium-air battery could help double EV range (World Industrial Reporter, 2017). https://worldindustrialreporter.com/samsungs-lithium-airbattery-could-help-double-ev-range/amp/?from $=$ singlemessage\&isappinstalled $=0$.

65. Comparison of plug-in hybrid electric vehicle battery life across geographies and drive-cycles (National Renewable Energy Lab, 2012). https://www.nrel.gov/ docs/fy12osti/53817.pdf.

66. Electric car battery life (BuyaCar, 2020). https:/www.buyacar.co.uk/cars/ economical-cars/electric-cars/1615/electric-car-battery-life.

67. EverBatt: A Closed-loop Battery Recycling Cost and Environmental Impacts Model (Argonne National Lab, 2019). https://publications.anl.gov/anlpubs/ 2019/07/153050.pdf.

68. Linda Gaines. Profitable Recycling of Low-Cobalt Lithium-Ion Batteries Will Depend on New Process Developments. One Earth 1, 413-415 (2019).

69. Reck, B. K. \& Graedel, T. E. Challenges in metal recycling. Science 337, 690-695 (2012).

70. Richa, K., Babbitt, C. W., Nenadic, N. G. \& Gaustad, G. Environmental tradeoffs across cascading lithium-ion battery life cycles. Int. J. Life Cycle Assess. 22, 66-81 (2017)

71. Identifying and Overcoming Critical Barriers to Widespread Second Use of PEV Batteries (National Renewable Energy Lab, 2015). https://www.osti.gov/ servlets/purl/1171780.

72. Ahmadi, L., Young, S. B., Fowler, M., Fraser, R. A. \& Achachlouei, M. A. A cascaded life cycle: reuse of electric vehicle lithium-ion battery packs in energy storage systems. Int. J. Life Cycle Assess. 22, 111-124 (2017).

73. Kamath, D., Arsenault, R., Kim, H. C. \& Anctil, A. Economic and environmental feasibility of second-life lithium-ion batteries as fast-charging energy storage. Environ. Sci. Technol. 54, 6878-6887 (2020).
74. Said, A. O., Lee, C. \& Stoliarov, S. I. Experimental investigation of cascading failure in 18650 lithium ion cell arrays: impact of cathode chemistry. J. Power Sources 446, 227347 (2020).

75. Casals, L. C., García, B. A. \& Canal, C. Second life batteries lifespan: rest of useful life and environmental analysis. J. Environ. Manag. 232, 354-363 (2019).

\section{Acknowledgements}

We acknowledge the China scholarship Council for supporting C.X. and the US Department of Energy Vehicle Technologies Office as well as Haixiang Lin. This project has also received funding from the European Union's Horizon 2020 research and innovation programme under grant agreement No 18225.

\section{Author contributions}

C.X. designed and conducted the research with input from B.S., Q.D, L.G., M.H., and A. T. B.S. and C.X. wrote the paper together with input of the other authors. Q.D. and L.G. designed the recycling scenarios and provided important input for the scenario development and the battery materials calculation using the BatPaC model.

\section{Competing interests}

The authors declare no competing interests.

\section{Additional information}

Supplementary information is available for this paper at https://doi.org/10.1038/s43246020-00095-x.

Correspondence and requests for materials should be addressed to B.S.

Peer review information Primary handling editor: John Plummer

Reprints and permission information is available at http://www.nature.com/reprints

Publisher's note Springer Nature remains neutral with regard to jurisdictional claims in published maps and institutional affiliations.

Open Access This article is licensed under a Creative Commons Attribution 4.0 International License, which permits use, sharing, adaptation, distribution and reproduction in any medium or format, as long as you give appropriate credit to the original author(s) and the source, provide a link to the Creative Commons license, and indicate if changes were made. The images or other third party material in this article are included in the article's Creative Commons license, unless indicated otherwise in a credit line to the material. If material is not included in the article's Creative Commons license and your intended use is not permitted by statutory regulation or exceeds the permitted use, you will need to obtain permission directly from the copyright holder. To view a copy of this license, visit http://creativecommons.org/ licenses/by/4.0/.

(C) The Author(s) 2020 